\title{
GESTIÓN DE CONTROL PATRIMONIAL Y SU INFLUENCIA EN LAS ALTAS Y BAJAS DE BIENES MUEBLES DEL GOBIERNO REGIONAL DE TACNA, PERIODO 2016
}

\author{
MANAGEMENT OF PATRIMONIAL CONTROL AND ITS INFLUENCE ON THE HIGH AND LOWER \\ OF MOVABLE PROPERTY OF THE REGIONAL GOVERNMENT TACNA, PERIOD 2016.
}

Pamela Candy Chambilla Chambe ${ }^{1}$

Presentado: 21/07/2018

Aceptado: 20/08/2018

Publicado online:27/12/2018

\section{RESUMEN}

El presente trabajo de investigación, reúne los diferentes aspectos de la gestión de control patrimonial las mismas que influyen en las altas y bajas de los bienes muebles del Gobierno Regional de Tacna, en el periodo 2016; así mismo se recopiló información de procedimientos, registro y control de bienes, coordinación y supervisión, normas y directivas establecidas por la entidad del Gobierno Regional de Tacna. El trabajo que se desarrolló es no experimental, descriptivo y correlacional de acuerdo a la finalidad de la investigación. El área de investigación está enmarcada en la contabilidad gubernamental, debido a que es una actividad encaminada al análisis y la evaluación de los procedimientos, alta y baja de bienes muebles para una buena gestión de control patrimonial, a través de la evaluación de la eficiencia, eficacia, economía de la Entidad. La institución materia de estudio tiene deficiencias en el control de inventario esto se debe a que se recibe los inventarios físicos sin ser constatados con una verificación exhaustiva, así como los bienes que se encuentran obsoletos por los cambios tecnológicos, no teniendo una cantidad exacta de los bienes patrimoniales que están bajo la administración de la institución, así como personal no capacitado.

Palabras clave: Control patrimonial, registro y control, alta y baja.

\section{ABSTRACT}

The present research work brings together the different aspects of the management of patrimonial control, which influence the additions and cancellations of the movable property of the Regional Government of Tacna,

\footnotetext{
${ }^{1}$ Maestro en Contabilidad, Tributación y Auditoría
} 
in the 2016 period; Likewise, information on procedures, registration and control of assets, coordination and supervision, norms and directives established by the entity of the Regional Government of Tacna was compiled. The work that was developed is not experimental, descriptive and correlational according to the purpose of the research. The research area is framed in government accounting, because it is an activity aimed at the analysis and evaluation of procedures, registration and removal of movable assets for a good management of patrimonial control, through the evaluation of efficiency, effectiveness, economy of the Entity. The institution subject of study has deficiencies in the control of inventory, this is due to the fact that physical inventories are received without being verified with exhaustive verification, as well as the goods that are obsolete due to technological changes, not having an exact quantity of the assets that are under the administration of the institution, as well as untrained personnel.

Key Words: Property control, registration and control, high and low.

\section{INTRODUCCIÓN}

Actualmente son innumerables los criterios de registro e incorporación de los bienes al inventario patrimonial del Estado, el mismo que tiene como una de sus funciones importantes registrar, cuidar, controlar los bienes registrables, de manera uniforme, para lograr sus objetivos para el beneficio del país. En el Gobierno Regional de Tacna, la oficina de control patrimonial tiene la responsabilidad de proteger el patrimonio de la entidad, sin embargo, se observa que el personal de patrimonio solo hace la recepción los inventarios físicos más no se cumple en constatar la información relacionada al control de los bienes que se encuentran totalmente depreciados, no se cuenta con procedimientos, directivas que permitan controlar los bienes muebles. Asimismo, existen bienes que se encuentra obsoletos por los cambios tecnológicos, lo cual está causando que no se tenga una cantidad precisa de los bienes patrimoniales que están bajo la administración de la institución, los mismos que requieren ser registrados, custodiados y controlados correctamente a fin de que se esté cumpliendo con el objetivo con el que fueron asignados. El personal que labora no se encuentra lo suficientemente capacitado para desempeñar una buena labor.

En el Perú, las entidades públicas se rigen por la Ley № 29151 “Ley General del Sistema Nacional de Bienes Nacionales", aprobado con Decreto Supremo № 007-2008-Vivienda de fecha 15 de marzo del 2008, el cual se refiere al Control de Bienes Patrimoniales. El Gobierno Regional siendo entidad pública y perteneciente al Sistema Nacional de Bienes Estatales, por su condición se enmarca dentro de la normatividad emanada por la Superintendencia Nacional de Bienes Estatales. Bolaños (2014), menciona que el contar con un registro e inventario patrimonial actualizado y de fácil acceso tanto para investigación científica como para información ciudadana y por supuesto la creación de redes interinstitucionales, va a permitir avanzar de manera más rápida en su proceso de empoderamiento de su patrimonio. Castillo (2012), refiere que el control patrimonial de bienes no solo implica la aplicación de normas y procedimientos, sino también se debe integrar nuevos elementos que permitan mejorar la gestión en general. Fue importante llevar un buen control patrimonial para saber que bienes de la institución se encuentran en alta y que bienes habrá que darles de baja. López (2012 menciona que en el análisis FODA permite conocer las falencias respecto a la normativa que demora en la ejecución de actividades. Chávez (2014), detalla que el patrimonio de las cajas 
Municipales de Ahorro se puede seguir incrementando el patrimonio con la incursión de socios inversionistas.

Se entiende por control del patrimonio a la evaluación de los bienes muebles de propiedad estatal, los descritos en el Catálogo Nacional de Bienes Muebles del Estado, así como todos aquellos bienes que sin estarlo son susceptibles de ser incorporados al patrimonio estatal. (Castañeda, 2010). Gómez (2016) lo define, como el ciclo de vida de un activo patrimonial desde la entrada del mismo en la entidad, hasta la salida del activo y las posteriores consecuencias que puedan producirse o derivarse de una gestión. (Peñaranda, 2015) refiere que el patrimonio está constituido por el conjunto de sus bienes y derechos, cualquiera sea su naturaleza y el título de su adquisición o aquel en virtud del cual les hayan sido atribuidos. La Unidad de Control Patrimonial obedece a la adscripción del Sistema Nacional de Bienes Estatales (Quiñonez, 2014) y tiene por finalidad definir los procedimientos y mecanismos a través de los cuales las entidades públicas realizarán las acciones legales, técnicas y administrativas pertinentes. Garantiza que los actos administrativos que sobre bienes de propiedad realicen las entidades públicas, protejan el interés general. (Manrique, 2014). Medina (2014), considera que el patrimonio es un conjunto de bienes cuyo vínculo no es la persona sino el fin jurídicamente perseguido, por lo tanto, pueden varias masas patrimoniales encontrarse en manos de una misma persona que el control patrimonial identifica y codifica los bienes patrimoniales adquiridos, de acuerdo a su naturaleza, asignándoles el respectivo valor monetario. (Abanto, 2010).

Se denomina bienes patrimoniales a "todos aquellos recursos materiales susceptibles de ser pesados, medidos, contados, verificados adquiridos por la entidad a fin de ser asignados en uso de sus organismos integrantes para el logro de sus objetivos y alcance de sus metas, sean a corto, mediano o largo plazo, según haya sido planificadas oportunamente." (Machaca, 2011). Vera (2009), explica que los bienes patrimoniales, por su naturaleza, durabilidad, valor unitario y destino incrementan el patrimonio del Estado.

La Superintendencia Nacional de Bienes Estatales supervisará la presencia física de los bienes según muestra obtenida del último inventario remitido a la Superintendencia Nacional de Bienes Estatales, debiendo estar debidamente sustentados los actos de gestión realizados sobre los bienes, de conformidad con la presente directiva. (Directiva N001-2015/SBN, aprobado con Resolución Nº46-2015/SBN).

\section{Objetivos}

1. Evaluar como los inventarios influyen en las altas y bajas de bienes muebles del Gobierno Regional de Tacna.

2. Determinar de qué manera el registro y control influye en las altas y bajas de bienes muebles Gobierno Regional de Tacna.

3. Analizar como la coordinación y supervisión influye en las altas y bajas de bienes muebles del Gobierno Regional de Tacna.

\section{METOdOLOGÍA}

investigación básica pura de nivel descriptivo, no experimental transaccional. Se realizó en el Gobierno Regional de Tacna. La población estuvo conformada por 40 servidores de las áreas de Administración, Control Patrimonial, Contabilidad, Abastecimiento, Tesorería y Recursos Humanos. Se aplicó un cuestionario dirigido a los servidores administrativos del Gobierno Regional de Tacna, para la evaluación de las variables: Gestión de Control patrimonial y las altas y bajas de los bienes muebles. 


\section{RESULTADOS}

En lo que se refiere a si se efectúa los inventarios de manera oportuna, el 55\% indica que algunas veces, el $35 \%$ indica que casi siempre, el $10 \%$ indica que casi nunca.

Respecto a los inventarios con contabilidad, el $50 \%$ indica que algunas veces, el $30 \%$ indica que casi siempre, el $15 \%$ indica que casi nunca y el $5 \%$ indica que siempre. En lo que se respecta a si se informa oportunamente los bienes sobrantes y faltantes, el $45 \%$ indica que algunas veces, el $30 \%$ indica que casi nunca y el $25 \%$ indica que casi siempre. Si se registra adecuadamente los activos fijos, el $43 \%$ indica que algunas veces, el $25 \%$ indica que casi nunca. A si se cuenta con procedimientos adecuados para el control de activos, el $50 \%$ indica que algunas veces, el $25 \%$ indica que casi siempre. En lo que se refiere a si el personal conoce las características para considerar un bien como activo fijo, el $40 \%$ indica que algunas veces, el $30 \%$ indica que casi nunca. Con respecto a si se cuenta con las directivas internas para el control de activos depreciados, el $43 \%$ indica que algunas veces, el $25 \%$ indica que casi nunca. Si se informa a contabilidad el importe de los activos depreciados, el 50\% indica que algunas veces, el $25 \%$ indica que casi nunca. Respecto a si los activos fijos antes de su entrega al usuario son codificados, el $42 \%$ indica que algunas veces, el $25 \%$ indica que casi nunca, el $20 \%$ indica que casi siempre. A si cuenta con un presupuesto para el mantenimiento de los activos de la entidad, el $40 \%$ indica que algunas veces, el $30 \%$ indica que casi nunca. Respecto a si existe un control para el desplazamiento de los activos fijos, el $45 \%$ indica que algunas veces, el $30 \%$ indica que casi nunca, el $18 \%$ indica que casi siempre. En lo que se refiere a si se efectúan los correctivos necesarios sobre los bienes sobrantes, el $40 \%$ indica que algunas veces, el $30 \%$ indica que casi nunca.

Al consultar si se revalúan oportunamente los activos depreciados de acuerdo a norma, el $43 \%$ indica que casi nunca, el $40 \%$ indica que algunas veces, el $12 \%$ indica que casi siempre y finalmente el $5 \%$ indica que nunca. Respecto a si los bienes no depreciables se informan a contabilidad para su registro mensualmente, el $43 \%$ indica que algunas veces, el $27 \%$ indica que casi siempre. Según la depreciación de bienes de acuerdo a la vida útil a si es realizada de manera adecuada, el $47 \%$ indica que algunas veces, el $27 \%$ indica que casi nunca, el $13 \%$ indica que casi siempre. En lo que respecta que, si a los bienes reparados se les asigna una nueva vida útil, el $45 \%$ indica que algunas veces, el $25 \%$ indica que casi nunca, el $20 \%$ indica que casi siempre y finalmente el $10 \%$ indica que siempre. En lo que se refiere a si las tasas de depreciación de los bienes dado de alta son adecuadas, el $55 \%$ indica que algunas veces, el $30 \%$ indica que casi siempre. A si se aplican las normas adecuadamente en el control de la vida útil, el $50 \%$ indica que algunas veces, el $25 \%$ indica que casi nunca. Respecto a si existe un control adecuado de los bienes que no se encuentran en uso, el $40 \%$ indica que casi nunca, el $32 \%$ indica que algunas veces, el $15 \%$ indica que casi siempre. A si los bienes obsoletos por cambio tecnológico son dados de baja oportunamente, el $45 \%$ indica que casi nunca, el $38 \%$ indica que algunas veces. En lo que se refiere a si se informa sobre los bienes en desuso para el tratamiento respectivo, el $42 \%$ indica que casi nunca, el $40 \%$ indica que algunas veces. A si se tiene procedimientos internos para el tratamiento de bienes obsoletos, el $45 \%$ indica que algunas veces, el $25 \%$ indica que casi nunca, el $18 \%$ indica que casi siempre, y el $12 \%$ indica que nunca.

\section{DISCUSIÓN}


La gestión de control patrimonial influye de manera directa en las altas y bajas de los bienes muebles del Gobierno Regional de Tacna, periodo 2016, asimismo los inventarios, el registro y control, la coordinación y supervisión viene influyendo en el alta y baja de bienes muebles del Gobierno Regional de Tacna. Se pudo constatar que el personal no se encuentra capacitado, no se cuenta con directivas internas actualizadas, también se observa que no existe un control y tratamiento adecuado de los bienes que son dados de alta y baja, además que los bienes obsoletos no son dados de baja oportunamente, no mostrando veracidad en los estados financieros de la entidad, a la vez no cumpliendo con las directivas vigentes de economía y finanzas y de la Superintendencia Nacional de Bienes y Servicios. Castillo (2012) explica que la gestión de control patrimonial en las entidades públicas demanda de sus actores, mediatos e inmediatos no solo la aplicación convencional de normas y procedimientos, sino también la innovación e integración de nuevos elementos para mejorar la gestión en general, siendo necesario que el personal con el que se trabaja se encuentre altamente capacitado, asimismo en el Gobierno Regional de Tacna es necesario que el personal este en constante capacitación y se encuentre actualizado en la aplicación de normas y procedimientos que deben ejecutarse al trabajo que vienen realizando para poder brindar un mayor aporte, asimismo dar el tratamiento adecuado a los bienes que son obsoletos, esto implica darlos de baja en su debido momento para que posteriormente no repercuta en los estados financieros de la entidad.

No se está aplicando procedimientos y normativas para la alta y baja de bienes, repercutiendo en el patrimonio de la Entidad. No se viene trabajando de manera correcta, puesto que el personal de la oficina de patrimonio recibe los inventarios de las diferentes áreas, mas no se realiza la verificación al $100 \%$ de la existencia de dichos bienes. No se canaliza una conciliación de manera oportuna con el área de contabilidad, repercutiendo en los estados financieros de la entidad. No se cuenta con directivas que permitan controlar los bienes que son obsoletos por los cambios tecnológicos y de ser necesario darlos de baja. La Oficina de Control Patrimonial en coordinación con la Oficina Regional de Administración y la Dirección Ejecutiva de Contabilidad, deberán implementar los procedimientos necesarios que permitan controlar y dar el mejor tratamiento al alta y baja de bienes muebles del Gobierno Regional de Tacna. Es necesario, elaborar las estrategias necesarias que permitan mejorar el control de inventarios, así como realizar las conciliaciones de manera mensual para la toma de decisiones, para que con ello la presentación de la información financiera sea fidedigna. Implementar directivas que permitan llevar el control adecuado de los bienes que son obsoletos por cambios tecnológicos, los mismos que deberán ser dados de baja, con el fin de disponer de bienes que sean necesarios para la institución.

\section{REFERENCIAS BIBLIOGRÁFICAS}

Abanto, C. (2010). El proceso de mejoramiento de patrimonio e implementación del sistema de control interno en una entidad pública.

Bolaños, A.C. (2014). Estrategias de gestión del patrimonio cultural en los GAD: Caso Canton Urcuqui 2013-2014 (Tesis de Maestría). Universidad de postgrado del estado, quito-Ecuador.

Castañeda Santos, Victoriano (2006). Manual para la Administración de Bienes Patrimoniales Estatales. Lima: Real Distribuidora

Castañeda, V. (2010). Manual para la Administración de Bienes Patrimoniales Estatales. Lima: 4 ta edición. 
Castañeda, V. (2003). Manual para la Administración de Bienes Patrimoniales. Lima, Perú: CEPREACCSA EIRL

Castillo, B. (2012). Propuesta para el manejo adecuado de los bienes patrimoniales en Instituciones Educativas (Tesis de titulación). Universidad de Panamá.

Castillo, Y. (2009). Saneamiento de bienes muebles. Primera edición

Chávez, P. V. (2014). Reforzamiento patrimonial para las Cajas Municipales de Ahorro y crédito (Tesis de Maestría). Pontificia Universidad Católica del Perú.

Directiva $N^{\circ}$ 001-2015/SBN. Procedimientos de Gestión de los Bienes muebles Estatales, aprobado con Resolución N046-2015/SBN

Directiva Nº01-97/SBN-UG-CIMN. (1997). Normas para la Catalogación de Bienes Muebles del Estado. Lima, Perú.

Fernández, R. (2015). Diccionario básico tributario contable.

Gómez, C. (2016). Gestión patrimonial

López, F. (2012). Propuestas de mejora al proceso de administración de bienes muebles del departamento de contabilidad sección bienes muebles adscrito a la Gerencia de Finanzas de la corporación venezolana de Guayana (Tesis de Titulación). Universidad Nacional Experimental de Guayana.

Machaca Huanca, E. (2011). Control de Bienes Patrimoniales y su incidencia en el Estado de Situación Financiera de la Dirección Regional de Educación Puno periodos 2009 y 2010

Manrique, A. (2007). Gestión de control patrimonial de bienes muebles del Estado.

Medina, S. (2014). Definiciones y teorías sobre el patrimonio.

Montero (2012). La importancia de un eficiente control de inventario.

Peñaranda, R (2015). Los bienes patrimoniales

Quiñonez (2014). Control patrimonial un mundo diferente

Vera, M. (2009). Sistema de Abastecimiento Contrataciones del Estado Gestión de Almacenes y Control Patrimonial. Lima - Perú: Instituto Pacífico S.A.C. 